\title{
Requirement of Strain Based Casing Design and Basic Steps for Shale Gas Wells
}

\author{
Lihong Han ${ }^{1 *}$, Huali Zhang ${ }^{2}$, Bo Zeng ${ }^{2}$, Bin Xie ${ }^{3}$, Gangyao $\mathrm{Li}^{3}$, Jiawen Han ${ }^{4}$, Zhenhui Shu ${ }^{3}$, Jianjun Wang ${ }^{1}$ and \\ Shangyu Yang ${ }^{1 *}$ \\ ${ }^{1}$ State key Laboratory for Performance and Structure Safety of Petroleum Tubular Goods and Equipment Materials \& CNPC Tubular Goods Research \\ Institute, China
}

${ }^{2}$ PetroChina Southwest Oil \& Gas Field Company, China

${ }^{3}$ PetroChina Xinjiang Oil field Company, China

${ }^{4}$ Xi'an Gaoxin No.1 School, China

Submission: April 22, 2019; Published: May 03, 2019

*Corresponding author: Lihong Han and Shangyu Yang, State key Laboratory for Performance and Structure Safety of Petroleum Tubular Goods and Equipment Materials, CNPC Tubular Goods Research Institute, Xi'an, Shaanxi, 710077, China

\section{Abstract}

The failure modes and mechanisms were analyzed aiming at many casings' radial deformation for shale gas wells in Sichuan district of China. It is considered that the casing deformation belongs to strain control mode instead of usual stress mode, where the formation lateral slip was determined as the dominating factor. The usual stress-based casing design was considered insufficient for this environment, and the new strainbased casing design method should be established to assure the casing's adaptivity to slipping formation for shale gas wells. For the new method the limited casing deformation is allowed when the bridge plug can successfully pass during hydrofracture process, which is the basic and the only design principle. Many factors should be evaluated and integrated to achieve quantitative evaluation model including geology feature, wellbore trajectory, cement sheath property, casing material and hydrofracture process. The basic steps for this design was proposed including the quantification of service environment from logging data, determination of casing deforming capability and cement sheath accommodation capability for radial slip from formation and then the final integrated design model could be established to supporting the factual engineering.

Keywords: Shale gas well; Strain based casing design; Deformation transfer; Integrated design

\section{Introduction}

Table 1: Shale gas reservoir environmental difference between Sichuan and North America.

\begin{tabular}{|c|c|c|c|c|c|c|c|}
\hline & \multirow{2}{*}{ Basin } & \multirow{2}{*}{ Depth /m } & \multicolumn{2}{|c|}{ Horizonal Stress/MPa } & \multirow{2}{*}{ Vertical Stress /Mpa } & \multirow{2}{*}{$\begin{array}{l}\text { Hydrofractur } \\
\text { Pressure /MPa }\end{array}$} & \multirow{2}{*}{$\begin{array}{c}\text { Reservoir } \\
\text { Thickness /m }\end{array}$} \\
\hline & & & Maximum & Minimum & & & \\
\hline \multirow{3}{*}{$\begin{array}{l}\text { North } \\
\text { America }\end{array}$} & Barnett & \multirow{3}{*}{$1500-2000$} & $34-43.4$ & $32-42$ & - & \multirow{3}{*}{$60-80$} & \multirow{3}{*}{$30-60$} \\
\hline & Marcellus & & 41.7 & 39.2 & 57.4 & & \\
\hline & Eagle ford & & 58.6 & 56.5 & 66.4 & & \\
\hline \multirow{4}{*}{ CW-China } & Wei 201-H1 & \multirow{4}{*}{$2000-4000$} & 48 & 29 & 35 & \multirow{4}{*}{$70-100$} & \multirow{4}{*}{$5-40$} \\
\hline & Wei 201-H3 & & 67 & 46 & 61 & & \\
\hline & Ning 1 & & 86 & 57.8 & 57 & & \\
\hline & Ning 2 & & 84 & 66 & 50 & & \\
\hline
\end{tabular}

Southwest oil and gas field in Sichuan is the key shale gas exploring district in China where many casing deformations has occurred and became a bottleneck for shale gas industry [1,2]. For shale gas wells the domestic process is hydrofracture on decades of horizontal sections. In 2018 the casing deformation rate there has reached about $50 \%$ for the new wells, and about $10.2 \%$ horizontal sections can't be fractured normally and be abandoned due to radial deformation of casing. Compared with North America, the gas reservoir in Sichuan are more complex with deep and thin layer, high and heterogeneous in-situ stress accompanying with abundant geology cracks and faults, as shown in Table 1. For petroleum industry the traditional method belongs to stress-based casing design where the strength is the key parameter $[3,4]$, and the plastic deformation is not allowed for 
casing. However, the radial deformation of casing is up to $25 \mathrm{~mm}$ according to the logging data with typical shear or collapse mode, as shown in Figure 1 \& 2. Obviously the casing deformation is inevitable for such a large formation slip and even the stronger casing like $160 \mathrm{ksi}$ with $16 \mathrm{~mm}$ wall thickness tried there has also no obvious effect, and so it is rather urgent for the engineering to propose and form a new casing design to prevent excessive radial deformation and assure the bridge plug to pass for normal field operations.

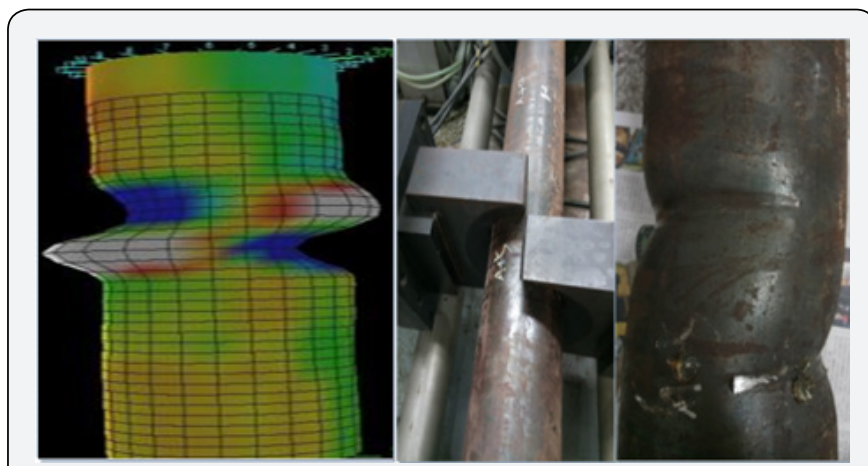

Figure 1: Shear failure and mechanism.
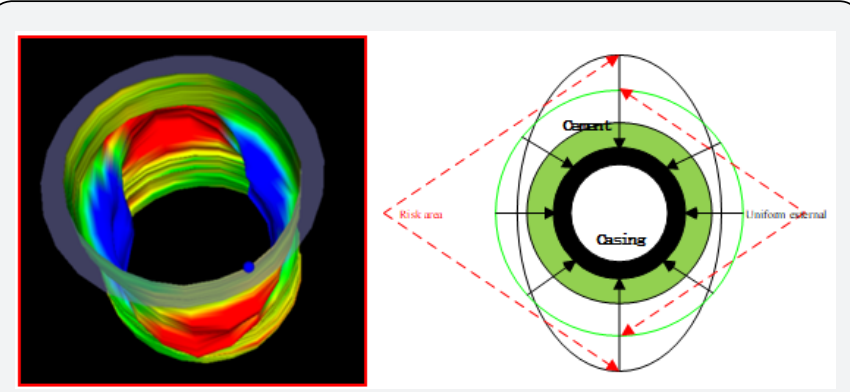

Figure 2: Inhomogeneous collapse failure and mechanism.

Casing Radial Deformation Mode and Mechanisms

The logging data to shale gas wells shows there are three modes with different mechanisms resulting in obvious radial deformation where the formation motion is always dominant factor.

\section{Shear deformation from formation slip}

This mode is shown in Figure 1. Obviously, the formation shear slip is the dominant factor which directly caused a large transverse displacement on casing, which must follow to deform because it has a limited elastic limit and the plastic deformation will occur inevitably [5]. This formation motion comes from the separation and slip of weak shale rock interface, moving of geology cracks or faults under the frequent stimulation of hydrofracture [6]. This can also be proved by many engineering cases. For example, the casing radial deformation has occurred in Ning-H4-3 well but it has not experienced hydrofracture operation. In fact, this deformation comes from the operation of its neighborhood wells where the casing was sheared obviously. For different wells there is only the single medium of formation through which different wells can be connected.

\section{Collapse deformation from non-uniform geology stress}

The geology stress in Sichuan has obvious biaxial inhomogeneity [7] as shown in Table 2, which can easily cause casing failure. Compared with the usual design method where the uniform geology stress was applied around the casing, this nonuniform feature is much easier to introduce some risk areas with high directional stress and then result in collapse deformation with typical ellipse outline as shown in Figure 2.

\section{Combined deformation}

It is unavoidable for casing string to experience many loads including of non-uniform geology stress and artificial loads from engineering operation like tension, compression, bending, and friction and so on. As described above, the formation motion is very common in Sichuan and the casing string must also bear this kind displacement action simultaneously and so the engineering failure is usually in combined deformation modes for shale gas casing.

\section{Status of Strain based Casing Design}

The concept of strain-based design for casing is from Canada where many casing failures have happened in thermal wells $[8,9]$. However, the factual engineering design and application comes from China in thermal wells (Dominated by the author's team), which has formed a China national standard [10]. The casing deformation of shale gas wells in Sichuan area is largely controlled by formation movement, which results in local stress and strain concentration on the casing. This is significantly different from the casing failure of thermal wells because the latter belongs to overall and nearly uniform plastic deformation along the longitudinal direction throughout the whole casing string due to large temperature changes in wellbore [11]. Moreover, the slip of shale formation belongs to random distribution, which is significantly related to well trajectory, fracturing technology and geological migration, and so no one can exactly predict the failure location because of the complexity and randomness of the downhole factors. Therefore, it is not realistic to try to do theoretical prediction according to the geology migration aiming at preventing casing failure. In the past ten years lots of predictions have been done but the casing failure is continually arising there.

\section{Feasibility of Strain based Casing Design for Shale Gas Wells}

As mentioned above, it is difficult to obtain the actual service environment for the casing string of shale gas well according to the current theoretical prediction method. However, the casing material has definite deforming behaviors, which can be used to achieve the quantitative stress and displacement load according to the logging data on deformed casing. This reverse deduction can supply close boundary conditions for the coming wells in the same area as shown in Table 2.

The next question is how to achieve the actual capability of casing products, without which no one can evaluate the application of casing products. For this full-scale test dominated 
by displacement and non-uniform geology stress there is very lack of valid equipment to do this throughout the world. Fortunately, the author has noticed this question and independently designed

Table 2: Geology stress reversion analysis results. a new evaluation device for this service environment in 2016. And now this device has been developed well and used to related casing test for shale gas wells, as shown in Figure 3.

\begin{tabular}{|c|c|c|c|c|c|}
\hline \multirow[b]{2}{*}{ Deformation Position } & \multirow[b]{2}{*}{$\operatorname{Dog} \operatorname{Leg}\left({ }^{\circ} / 30 \mathrm{~m}\right)$} & \multirow[b]{2}{*}{ Shear Load /Ton } & \multicolumn{3}{|c|}{ Geology stress / MPa } \\
\hline & & & $\begin{array}{l}\text { Maximum Horizonal } \\
\text { Stress }\end{array}$ & $\begin{array}{c}\text { Minimum Horizonal } \\
\text { Stress }\end{array}$ & $\begin{array}{c}\text { Max to Min Stress } \\
\text { Ratio }\end{array}$ \\
\hline Point 1 & 7.73 & 50 & 65 & 50 & 1.3 \\
\hline Point 2 & 7.73 & 20 & 65 & 45 & 1.44 \\
\hline Point 3 & 7.73 & 10 & 65 & 55 & 1.18 \\
\hline
\end{tabular}

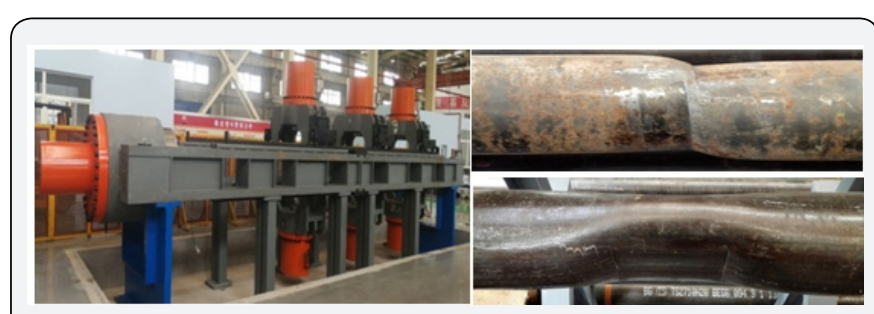

Figure 3: Test device and results for shear and collapse.

Field data shows that the casing radial deformation can reach up to $25 \mathrm{~mm}$, which cannot be absorbed only by casing because so much deformation will result in a small room where the following bridge plug cannot pass and the hydrofracture operation will be terminated. There is only one medium between casing and formation, i.e. cement sheath, which should absorb part of displacement from slipping formation. So, the current tendency to continually improve the toughness of cement should be stopped and only brittle one can easily break to accommodate some formation displacement. Correspondingly the cement sheath should have some voids to present moving room for broken cement pieces, and we can call this method an integrated strainbased casing design with deformation transferring capability between casing and the cement sheath, as described in Figure 4.
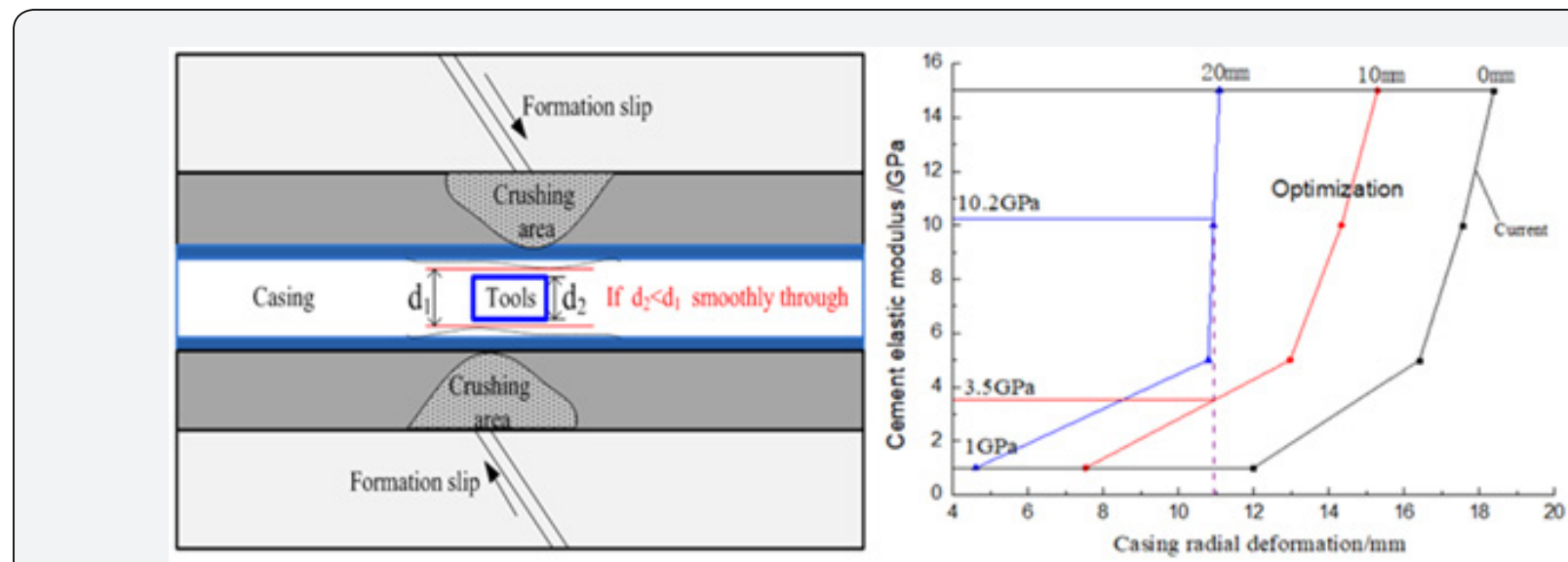

Figure 4: Deformation transfer design and prediction.

There are two questions for this method. First, the weakened cement sheath should still be able to separate different rock layers in the longitudinal direction to prevent their collapse and connection with each other. The logging data for shale gas wells shows that the casing deformation is usually not beyond 2-4 meters length, which belongs to a local strain concentration and so it is unnecessary to worry about the first question. Second question is how to artificially make voids in cement sheath. For this purpose, we can introduce some hard and brittle hollow particles like ceramic or glass ball, which can be put into reservoir together with the cement mud during the period of well cementation. These particles will accelerate the local crush of cement sheath and provide moving room for broken cement pieces when the outer formation movement occurs. Of course, lots of practice still needs to be done to certificate the validity of new method for preventing excessive casing deformation.
Basic Steps for Strain based Casing Design in Shale Gas Wells

For controlling the casing deformation in shale gas well of China, strain-based casing design method should and can be established as an integrated design, which should contain the following steps.

a) To quantitatively and reversal determine the downhole stress and displacement on casing string.

b) To determine the casing capability for above conditions through key tests and simulation analysis.

c) To determine the cement transferring capability on formation slip through experimental method under assistance of hollow particles. 
d) To achieve the integrated design model for casing, cement sheath, hollow particle, and other factors.

e) To do field experiment for shale gas wells and to certificate the validity of new method.

\section{Conclusion and Suggestions}

The large amount of casing radial deformation in shale gas wells in China was caused and dominated by the geology movement including of shale rock separation and slip, geology cracks and fault migration, and so strain based design method should be established to prevent further casing failure. Plastic deformation of casing should be allowed but must be constrained and many factors should be introduced as an integrated method such as casing material, cement property, geology feature, hollow particles, engineering process and so on. The basic steps for strain-based design were proposed, which still needs practical certification.

\section{Acknowledgement}

This paper was finically supported by the Natural Science Foundation of China (51574278, U1762211) , National key Technologies R\&D Program of China (2016ZX05022005, 2017ZX05009003-004), CNPC Basic Research Project(2019A-3911) and Shaanxi Outstanding Youth Fund(2018JC-030). Special thanks is given to my daughter for her flash idea to represent cement with brittle glass.

\section{References}

1. Caineng Z, Zhi Y, Dongbo H, Jian L, Yunsheng W et al. (2018) Theory, technology and prospects of conventional and unconventional natural gas. Petroleum Exploration and Development 45(4): 575-587.
2. Guo X, Li Y, Liu R, Wang Q (2014) Characteristics and controlling factors of micro pore structures of longmaxi shale play in the jiaoshiba area, Sichuan basin. Natural Gas Industry B 1(2): 165-171.

3. ISO/TR 10400 (2007) Petroleum and natural gas industries-equations and calculations for the properties of casing, tubing, drill pipe and line pipe used as casing and tubing.

4. API SPEC 5CT (2018) Specification for casing and tubing. (10 th Edn), Washington, DC: API, USA.

5. Cui Yueming (2015) Mechanism of formation slippage and shear casing damage of the marker bed in sazhong development area of daqingoil field [D]. Northeast petroleum university.

6. Wang Suling, Yang Lei (2018) Numerical simulation and influencing factors analysis on casing shear damage in shale layer. China Petroleum Machinery 46(1): 100-105.

7. Hong Guobing, Chen Mian, Lu Yunhu, Jin Yan (2017) Study on the anisotropy characteristics of deep shale in the southern Sichuan basin and their impacts on fracturing pressure. Petroleum drilling techniques 46(3): 78-85.

8. Xiejueren (2008) A study of strain based design criteria for thermal well casings, world heavy oil conference, Edmonton, Canada, paper number: 2008-388.

9. IRP (2002) Industry recommended practices for heavy oil and oil sand operations, Vol 3.

10.GB/T 34907 (2017) Technical specifications and fitness for service evaluation method for thermal well casing under cyclic steam simulation process.

11. Han L, Wang H, Wang J, Xie B, Wu X (2018) Strain based casing design for cyclic steam simulation wells[J]. SPE Production \& operations, SPE180703 33(2): 1-10. 